Heylen, J., De Raedt, R., Verbruggen, F., \& Bosmans, G. (in press). Attachment and self-regulation performance in preadolescence. Journal of Social and Personal Relationships.

\title{
Attachment and Self-regulation Performance in Preadolescence
} Joke Heylen $^{1}$, Rudi De Raedt ${ }^{2}$, Frederick Verbruggen ${ }^{3}$, and Guy Bosmans ${ }^{1}$

${ }^{1}$ Parenting and Special Education Research Group, KU Leuven, Belgium.

${ }^{2}$ Department of Experimental Clinical and Health Psychology, Ghent University, Belgium.

${ }^{3}$ Department of Psychology, University of Exeter, United Kingdom

This research was supported in part by Grant G.0934.12 of the Research Foundation Flanders (FWO), and Grants OT/12/043 and CREA/12/004 from the Research Fund KU Leuven, Belgium. Frederick Verbruggen is supported by a starting grant from the European Research Council (ERC) under the European Union's Seventh Framework Programme (FP7/2007-2013)/ERC Grant Agreement No. 312445 .

Correspondence concerning this article should be addressed to Joke Heylen, Parenting and Special Education Research Group, KU Leuven, Leopold Vanderkelenstraat 32 - bus 3765, Leuven, 3000, Belgium.

Email: joke.heylen1@kuleuven.be 


\begin{abstract}
In preadolescence, research has shown links between the quality of children's attachment relationships and children's perceived self-regulatory abilities. However, less research has focused on the association between attachment and preadolescents' self-regulation performance. In a sample of 120 children, aged 9-13, we administered questionnaires to assess trust in maternal support, and anxious and avoidant attachment. In addition, mothers reported about their children's selfregulatory abilities, and children performed the Stop-Signal Task. Consistent with predictions, correlation analyses revealed that a more insecure attachment relationship with mother was not only associated with less self-regulatory abilities as perceived by mother, but also with preadolescents' lower self-regulation performance in the Stop-Signal Task. Adding demographic variables as covariates to the analyses did not significantly alter these effects. The current multimethod study contributes to an increasing awareness of the importance of the quality of the motherchild relationship for children's self-regulation.
\end{abstract}

Keywords: attachment, self-regulation, effortful control, Stop-Signal Task, preadolescence 
Self-regulation, the capacity to flexibly control attention and behaviour in order to respond appropriately to both internal and environmental demands, is crucial for adaptive development (Carver \& Scheier, 2011). The ability to regulate the self allows a child to voluntarily inhibit automatic, inappropriate responses and to activate and shift to appropriate responses when necessary. Self-regulation is critical in everyday life: it has been linked to multiple indicators of psychopathology (e.g., internalizing and externalizing problems), socioeconomic status (e.g., financial struggles), and crime (e.g., conviction of a criminal offence) across the lifespan (e.g., Eisenberg, Spinrad, \& Eggum, 2010).

Parent-child interactions have been postulated to play an important role in the development of children's self-regulatory abilities (Eisenberg et al., 2010; Sroufe, 1983). More precisely, children's attachment expectations, specifically their confidence in the availability of their caregiver, is supposed to be crucial for self-regulation development (Bowlby, 1973). On the one hand, trust in the caregiver's support fosters proximity seeking in times of distress allowing caregivers to act as a source of aid, gradually promoting children's own self-regulatory capacity. On the other hand a secure attachment relationship promotes more free exploration of the environment. This offers children the opportunity to further practice their self-regulatory abilities autonomously.

In line with the assumption that secure attachment promotes self-regulation development, recent neurocognitive research showed that the quality of the attachment relationship influences activation in the brain areas involved in self-regulation (e.g., Schneider-hassloff et al., 2016). Further evidence for the link between attachment and self-regulation comes from empirical studies from infancy to the first stages of middle childhood (e.g., Nordling, Boldt, O’Bleness, \& Kochanska, 2016; Viddal et al., 2015; West, Mathews, \& Kerns, 2013). However, studies in preadolescence are still sparse. Investigating the attachment-self-regulation association seems particularly relevant at this developmental period, as research suggests that during the transition to adolescence, self-regulation is especially malleable by contextual influences (King, Lengua, \& Monahan, 2013). 
The only study that examined whether preadolescents' self-regulatory capacity is linked to the quality of the attachment relationship with their caregiver, was conducted by Heylen et al. (2017). In two independent samples they found that decreased self-regulation was related to insecure attachment in general, as both a lack of trust in the caregiver's support and the insecure attachment styles (attachment anxiety and avoidance) were associated with less self-regulatory capacity. However, this study had one important limitation. Heylen et al. (2017) focused solely on the link between attachment and the mothers' and children's perception of children's self-regulation operationalized as effortful control, while a performance-based measure of self-regulation was not included.

Self-regulation has traditionally been studied from either an effortful control (Posner \& Rothbart, 2000) or an executive functioning perspective (Eslinger, 1996), with effortful control the focus of temperament research and primarily measured with questionnaires, and executive functioning the focus of the fields of cognitive neuroscience and cognitive psychology, and mainly assessed with performance-based tasks. Although effortful control and executive functions show positive associations in empirical studies and overlap conceptually (i.e. both constructs comprise inhibition -the ability to suppress behavioural responses when needed (Posner \& Rothbart, 2000)- as a central component), they are not the same (Zhou, Chen, \& Main, 2012). Therefore, the current study aimed to add to the findings of Heylen et al. (2017) by following the recommendations of Zhou et al. (2012) to focus on both self-regulation-related constructs. More specifically, we tested the hypothesis that in preadolescence insecure attachment in general, operationalized as less trust in maternal support, would not only be associated with children's self-regulatory abilities as reported by their mother, but also with lower performance on an executive function task. With regard to the unique contribution of the insecure attachment styles, we predicted that attachment anxiety would be linked to decreased self-regulation performance because children who are more anxiously attached are often overwhelmed by their emotions, interfering with the regulation of their attention and behaviour. For attachment avoidance, the prediction was less clear as some children who are 
more avoidantly attached might display more self-regulation because they are trained in suppressing their emotions, while at the same time these attempts to control themselves might deplete their self-regulatory capacity.

\section{Method}

\section{Participants}

One hundred twenty children ( 55 boys, 65 girls) of an urban community sample with ages ranging from 9 to 13 years old $(M=10.61, S D=1.03)$ participated in the study. The majority of the children $(83.3 \%)$ lived with both parents. Mother was a primary caregiver in the first three years of life for most (97.5\%) of the children. All children reported attachment towards their biological mother. Regarding maternal highest level of education, 4 (3.3\%) mothers had an elementary school degree, 23 (19.2\%) mothers had a high school degree, 53 (44.2\%) mothers had a post-high-school technical training or a technical bachelor's degree, and 40 (33.3\%) mothers had a higher degree.

\section{Measures}

The trust subscale of the People in My Life Questionnaire (PIML; Ridenour, Greenberg, \& Cook, 2006) was used to assess children's trust in the availability and support of their mother (e.g., "I can count on my mother to help me when I have a problem."). Children responded to 10 items on a 4-point Likert-scale. The internal consistency ratings of the questionnaires are presented in Table 1.

The Experiences in Close Relationships Scale-Revised Child version (ECR-RC; Brenning, Soenens, Braet, \& Bosmans, 2011) was administered to measure attachment anxiety, tapping into feelings of fear of abandonment and strong desires for interpersonal merger (e.g., "I worry about being abandoned by my mother."), and attachment avoidance, tapping into discomfort with dependence and intimate self-disclosure towards mother (e.g., "I prefer not to show to my mother how I feel deep down."). Children were asked to rate each of 36 items on a 7-point Likert-scale.

The Stop-Signal Task (SST; for a detailed description of the task see Verbruggen, Logan, \& Stevens, 2008) was used as the executive function measure to assess children's self-regulation performance. This experimental paradigm is a widely used tool to study the cognitive and neural 
mechanisms of response inhibition. The task consists of two different kinds of trials (see Figure 1). On go-trials, children are required to discriminate (press right or left) between two shapes, a circle versus a square (the go-stimuli), as fast and accurately as possible. Stop-trials start with the presentation of one of the go-stimuli, followed by an auditory stop-signal. Children are instructed to inhibit their primary go-response whenever the stop-signal is given. Stop-signal delay (SSD) is the time between the go- and stop-signal. Initially the SSD is $250 \mathrm{~ms}$. In order to assure that each child can inhibit his/her response on approximately $50 \%$ of the stop-signal trials, SSD is continuously adjusted during the task using a staircase tracking mechanism: after each successful stop-trial (signalinhibit), SSD increases by $50 \mathrm{~ms}$, making it more difficult to inhibit the next go-response; after each failed stop-trial (signal-respond), SSD decreases by 50ms, making it easier to inhibit the next goresponse. The latency of the stop-process (stop-signal reaction time; SSRT), the main dependent variable of the task, was estimated using the integration method as recent research indicates that this is the more reliable estimation method (for a detailed description see Verbruggen, Chambers, \& Logan, 2013). A lower SSRT means that on average a child needs less time to inhibit a response that is already initiated, and thus indicates better self-regulation performance. The SST has shown moderate to good convergent, discriminant, and predictive validity in both clinical and community samples (e.g., Nichols \& Waschbusch, 2004).

The effortful control factor of the Early Adolescent Temperament Questionnaire-Revised (EATQ-R; Ellis \& Rothbart, 2001) was used to estimate children's self-regulatory capacity as perceived by their mother. Mothers responded to 18 items on a 5-point Likert-scale, tapping the activation (e.g., "If my child has a hard assignment to do, he gets started right away."), attentional (e.g., "It is easy for my child to really concentrate on homework problems."), and inhibitory control (e.g., "When someone tells my child to stop doing something, it is easy for him/her to stop.") of their children.

\section{Procedure}

Children and their mothers were invited to the laboratory as part of a broader study using a flyer distributed in the classrooms of the fourth, fifth, and sixth grades of elementary schools. All 
those who initially expressed interest gave their written informed consent. With regard to the parts of the procedure relevant for the current hypotheses, children filled out the attachment questionnaires before the SST was conducted. At the same time their mothers completed a demographic form, and the EATQ-R. The entire research procedure was approved by the university's ethical committee.

\section{Results}

\section{Preliminary analyses}

Data screening showed that two children did not complete the entire SST. Furthermore, as it is important to ensure that children are sufficiently engaged in the SST and none of the key assumptions of the SST procedure are violated, children were excluded when they missed $10 \%$ or more responses on the go trials, when they stopped on more than $75 \%$ or less than $25 \%$ of the stoptrials (Congdon et al., 2012), and when the mean go-trial reaction time was shorter than the mean signal-respond reaction time (Verbruggen \& Logan, 2015). For these reasons, all together 12 cases had to be removed from the analyses. Moreover, as studies have demonstrated that Ritalin affects children's performance on the SST (e.g., Schachar et al., 2008), 4 children whose mother reported that their child took Ritalin daily, were excluded from the analyses as well. Attachment scores of the children included in, and excluded from the present analyses did not significantly differ. Less than $0.1 \%$ of the values of the demographic and key variables under study were missing. As these data were MCAR, Little's MCAR test was not significant, $\chi^{2}(20)=18.29, p=.569$, we used the expectation maximization method to estimate the missing data, resulting in $n=104$ for all subsequent analyses. Sex, age, and maternal level of education were not related to any of the key variables under study.

\section{Attachment and self-regulation}

Descriptive statistics of the SST variables are presented in Table 2. Means and standard deviations of, and correlations between the key variables are shown in Table 1. A significant positive correlation emerged between trust and effortful control (measured with the EATQ-R), but neither attachment anxiety, nor attachment avoidance were significantly correlated with effortful control. 
In addition, in line with the hypothesis of the current study, trust was significantly negatively correlated with SSRT. To test the unique contribution of trust in predicting SSRT, sex, age, and maternal level of education were added as control variables in a multiple linear regression (MLR) analysis with SSRT as dependent variable and trust as predictor, $R^{2}=.06, F(4,99)=1.63, p=.173$. The unique effect of trust on SSRT was marginally significant, $b=-0.19, t(99)=-1.95, p=.054, f^{2}=0.04$. Furthermore, a significant positive correlation emerged between attachment anxiety and SSRT, and attachment avoidance was marginally correlated with SSRT. A MLR analysis was carried out with SSRT as dependent variable and attachment anxiety and avoidance as predictors, $R^{2}=.07, F(2,101)=3.51$, $p=.034$, to investigate unique links of SSRT with the two insecure attachment dimensions. Attachment anxiety remained marginally significantly associated with SSRT after controlling for attachment avoidance, $b=0.25, t(101)=1.97, p=.052, f^{2}=0.04$. However, there was no unique link between attachment avoidance and SSRT after taking attachment anxiety into account, $b=0.01$, $t(101)=0.09, p=0.927, f^{2}=.00$. Adding sex, age, and maternal level of education did not significantly alter these results, $R^{2}=.08, F(5,98)=1.77, p=.127$, with $B=0.52, t(98)=1.98, p=.051, f^{2}=0.04$, and $B=-0.02, t(98)=-0.13, p=.893, f^{2}=0.00$, for attachment anxiety and avoidance respectively.

\section{Discussion}

The current study aimed to add to the findings of Heylen et al. (2017) by investigating whether in preadolescence the quality of children's attachment relationship would not only be linked to children's self-regulatory abilities as perceived by their mother, but also to their self-regulation performance on an executive functioning task. In line with the findings of Heylen et al. (2017) preadolescents' effortful control was linked to trust in maternal support. However, in contrast to this previous study, no links were found between effortful control and the two insecure attachment styles specifically. In addition, the current study was the first to examine the association between the quality of children's attachment relationship and performance on a Stop-Signal Task in preadolescence. In this regard, the analyses showed that a lack of trust in the caregiver's support was also associated with decreased self-regulation performance. Moreover, attachment anxiety was 
linked to self-regulation performance, while attachment avoidance was not. As the link between attachment anxiety and self-regulation performance remained marginally significant even when controlling for attachment avoidance, these results suggest that the association between insecure attachment and self-regulation performance might be mostly attachment anxiety specific. The fact that controlling for demographic variables did not significantly alter the results, further contributes to the meaningfulness of these findings.

Taken together, the current results are consistent with Bowlby's (1973) assumption that children's attachment relationships provide a context in which children develop the capacity to regulate the self. The use of self-report measures in Heylen et al. (2017)'s study did not allow ruling out that the association between insecure attachment and a lack of self-regulatory abilities in preadolescence was inflated by mothers' and children's biased perception due to a negative relational dynamic. Instead, the current results are a stronger support for the claim that insecure attachment in preadolescence is specifically related to children's self-regulation capacity.

Some comments on the study design are important to mention. First, although prospective research in early childhood suggests that attachment in infancy was related to children's selfregulation several years later (e.g., Nordling et al., 2016), no cause-effect or developmental claims can be made based on the present cross-sectional data. Moreover, as research showed that there might be bidirectional associations between characteristics of the parent-child relationship and children's self-regulation (Sameroff, 2009), experimental and longitudinal studies are necessary to further unravel how attachment and self-regulation are related over time. Finally, one of the critiques on attachment theory is that it bears the risk to develop into a 'theory that all good things go together' (E. Waters, Corcoran, \& Anafarta, 2005). In a similar vein, the current study might unintentionally give the impression that we consider secure attachment synonymous to adequate self-regulation. However, the currently found modest effect sizes indicate neither that all securely attached children will have the best self-regulation skills, nor that all insecurely attached children will have limited self-regulation skills. Nevertheless, we do think that the current findings support the 
idea that a secure base context promotes children's self-regulation capacity development. Second, whereas the current paper at least suggests that children's explicit beliefs about the availability of their caregiver in times of need are linked to their self-regulation performance, the results rely solely on self-reported attachment. Although several studies have demonstrated the validity of selfreported attachment measures (e.g., Dujardin et al., 2016) replication of the findings with narrative or observational measures of the quality of the attachment relationship (e.g., T. E. A. Waters, Bosmans, Vandevivere, Dujardin, \& Waters, 2015) would strengthen the interpretation that the results specifically reflect a link between attachment and self-regulation. Third, in the current sample the reliability of the trust scale was only modest. However, repeating the main analyses with a factor score of the items of the trust scale did not significantly alter the results, suggesting that error variance in the trust scale in the current sample did not comprise the findings. Finally, the selfregulation task used in the current study is designed to assess inhibitory control, covering only one facet of the broader self-regulation construct (Zhou et al., 2012). Furthermore, one could wonder whether the Stop-Signal Task is an ecologically valid measure. Although, performance on a stopsignal task has been linked for example to children's hyperactive, impulsive and aggressive classroom behaviour (Solanto et al., 2001), future research should include a battery of executive function measures tapping into various aspects of self-regulation and using observations of self-regulatory behaviour in every-day life.

In spite of these limitations, the current findings shed further light on the theoretical link between the quality of children's attachment relationships and self-regulation in preadolescence, by demonstrating correlations between attachment ratings and measures of both perceived selfregulatory abilities and self-regulation performance. As attachment has been associated with neural correlates of self-regulation performance (e.g., Nash, Prentice, Hirsh, Mcgregor, \& Inzlicht, 2014), to further clarify how attachment and self-regulation are interrelated, future research should adopt a neuroscientific perspective. Clinically, practitioners should be aware that within the context of an insecure attachment relationship a lack of self-regulation might hamper children's progress during 
treatment. Hence, in order to facilitate progress it might be of particular importance to not only focus on training children's self-regulatory abilities, but also target their trust in the caregiver's support. 


\section{References}

Bowlby, J. (1973). Attachment and loss: Vol. 2. Separation: Anxiety and anger (Vol. II). New York, NY: Basic Books.

Brenning, K. M., Soenens, B., Braet, C., \& Bosmans, G. (2011). An adaptation of the Experiences in Close Relationships Scale-Revised for use with children and adolescents. Journal of Social and Personal Relationships, 28, 1048-1072. http://doi.org/10.1177/0265407511402418

Carver, C. S., \& Scheier, M. F. (2011). Self-regulation of action and affect. In K. D. Vohs \& R. F. Baumeister (Eds.), Handbook of self-regulation: Research, theory, and applications (2nd ed., pp. 3-21). New York, NY: Guilford Press.

Congdon, E., Mumford, J. A., Cohen, J. R., Galvan, A., Canli, T., \& Poldrack, R. A. (2012). Measurement and reliability of response inhibition. Frontiers in Psychology, 3, 1-10. http://doi.org/10.3389/fpsyg.2012.00037

Dujardin, A., Santens, T., Braet, C., De Raedt, R., Vos, P., Maes, B., \& Bosmans, G. (2016). Middle childhood support-seeking behavior during stress: Links with self-reported attachment and future depressive symptoms. Child Development, 87, 326-340. http://doi.org/10.1111/cdev.12491

Eisenberg, N., Spinrad, T. L., \& Eggum, N. D. (2010). Emotion-related self-regulation and its relation to children's maladjustment. Annual Review of Clinical Psychology, 6, 495-525. http://doi.org/10.1146/annurev.clinpsy.121208.131208

Ellis, L. K., \& Rothbart, M. K. (2001). Revision of the Early Adolescent Temperament Questionnaire. Poster presented at the biennial meeting of the Society for Research in Child Development. Mianneapolis, MN.

Eslinger, P. J. (1996). Conceptualizing describing and measuring components of executive function: A summary. In G. R. Lyon \& N. A. Krasnegor (Eds.), Attention, memory, and executive function (pp. 367-395). Baltimore, MD: Paul H. Brookes Publishing.

Heylen, J., Vasey, M. W., Dujardin, A., Vandevivere, E., Braet, C., De Raedt, R., \& Bosmans, G. (2017). 
Attachment and effortful control: Relationships with maladjustment in early adolescence. Journal of Early Adolescence, 37, 289-315. http://doi.org/10.1177/0272431615599063

King, K. M., Lengua, L. J., \& Monahan, K. C. (2013). Individual differences in the development of selfregulation during pre-adolescence: Connections to context and adjustment. Journal of Abnormal Child Psychology, 41, 57-69. http://doi.org/doi:10.1007/s10802-012-9665-0.

Nash, K., Prentice, M., Hirsh, J., Mcgregor, I., \& Inzlicht, M. (2014). Muted neural response to distress among securely attached people. Social Cognitive and Affective Neuroscience, 9, 1239-1245. http://doi.org/10.1093/scan/nst099

Nichols, S. L., \& Waschbusch, D. A. (2004). A review of the validity of laboratory cognitive tasks used to assess symptoms of ADHD. Child Psychiatry and Human Development, 34, 297-315. http://doi.org/10.1023/B:CHUD.0000020681.06865.97

Nordling, J. K., Boldt, L. J., O’Bleness, J., \& Kochanska, G. (2016). Effortful control mediates relations between children's attachment security and their regard for rules of conduct. Social Development, 25, 268-284. http://doi.org/10.1111/sode.12139

Posner, M. I., \& Rothbart, M. K. (2000). Developing mechanisms of self-regulation. Development and Psychopathology, 12, 472-441. http://doi.org/10.1017/S0954579400003096

Ridenour, T. A., Greenberg, M. T., \& Cook, E. T. (2006). Structure and validity of People In My Life: A self-report measure of attachment in late childhood. Journal of Youth and Adolescence, 35, 1037-1053. http://doi.org/10.1007/s10964-006-9070-5

Sameroff, A. J. (2009). The transactional model. In A. J. Sameroff (Ed.), The transactional model of development: How Children and contexts shape each other (6th ed., pp. 3-21). Washington, DC: American Psychological Association. http://doi.org/10.1037/11877-001

Schachar, R., Ickowicz, A., Crosbie, J., Donnelly, G. A. E., Reiz, J. L., Miceli, P. C., ... Darke, A. C. (2008). Cognitive and behavioral effects of multilayer-release methylphenidate in the treatment of children with attention-deficit/hyperactivity disorder. Journal of Child and Adolescent Psychopharmacology, 18(1), 11-24. http://doi.org/10.1089/cap.2007.0039 
Schneider-hassloff, H., Zwönitzer, A., Künster, A. K., Mayer, C., Ziegenhain, U., \& Kiefer, M. (2016). Emotional availability modulates electrophysiological correlates of executive functions in preschool children, 10, 1-17. http://doi.org/10.3389/fnhum.2016.00299

Solanto, M. V., Abikoff, H., Sonuga-barke, E., Schachar, R., Logan, G. D., Wigal, T., ... Turkel, E. (2001). The ecological validity of delay aversion and response inhibition as measures of impulsivity in AD/HD : A supplement to the NIMH multimodal treatment study of AD/HD, 29, 215-228. http://doi.org/10.1023/A:1010329714819

Sroufe, L. A. (1983). Infant-caregiver attachment and patterns of adaptation in preschool: The roots of maladaptation and competence. In M. PerImutter (Ed.), Minnesota symposium in child psychology (pp. 41-91). Hillsdale, NJ: Erlbaum.

Verbruggen, F., Chambers, C. D., \& Logan, G. D. (2013). Fictitious inhibitory differences: how skewness and slowing distort the estimation of stopping latencies. Psychological Science, 24, 352-362. http://doi.org/10.1177/0956797612457390

Verbruggen, F., \& Logan, G. D. (2015). Evidence for capacity sharing when stopping. Cognition, 142, 81-95. http://doi.org/10.1016/j.cognition.2015.05.014

Verbruggen, F., Logan, G. D., \& Stevens, M. A. (2008). STOP-IT: Windows executable software for the stop-signal paradigm. Behavior Research Methods, 40, 479-483.

http://doi.org/10.3758/BRM.40.2.479

Viddal, K. R., Berg-Nielsen, T. S., Wan, M. W., Green, J., Hygen, B. W., \& Wichstrøm, L. (2015). Secure attachment promotes the development of effortful control in boys. Attachment \& Human Development, 17, 319-335. http://doi.org/10.1080/14616734.2014.999098

Waters, E., Corcoran, D., \& Anafarta, M. (2005). Attachment, other relationships, and the theory that all good things go together. Human Development, 48, 80-84. http://doi.org/10.1159/000083217

Waters, T. E. A., Bosmans, G., Vandevivere, E., Dujardin, A., \& Waters, H. S. (2015). Secure base representations in middle childhood across two western cultures: Associations with parental 
attachment representations and maternal reports of behavior problems. Developmental

Psychology, 51, 1013-1025. http://doi.org/10.1037/a0039375

West, K. K., Mathews, B. L., \& Kerns, K. A. (2013). Mother-child attachment and cognitive performance in middle childhood: An examination of mediating mechanisms. Early Childhood Research Quarterly, 28, 259-270. http://doi.org/10.1016/j.ecresq.2012.07.005

Zhou, Q., Chen, S. H., \& Main, A. (2012). Commonalities and differences in the research on children's effortful control and executive function: A call for an integrated model of self-regulation. Child Development Perspectives, 6, 112-121. http://doi.org/10.1111/j.1750-8606.2011.00176.x 
Table 1

Correlations (Cohen's $\left.f^{2}\right)$, Means, Standard Deviations, and Cronbach's $\alpha$ 's of the key variables $(n=$ 104)

\begin{tabular}{|c|c|c|c|c|c|c|c|c|}
\hline Measure & 1 & 2 & 3 & 4 & 5 & 6 & 7 & 8 \\
\hline 1. Trust & 1 & & & & & & & \\
\hline 2. Attachment anxiety & $\begin{array}{l}-.47^{* * *} \\
(0.28)\end{array}$ & 1 & & & & & & \\
\hline 3. Attachment avoidance & $\begin{array}{l}-.48^{* * *} \\
(0.30)\end{array}$ & $\begin{array}{l}.64 * * * \\
(0.69)\end{array}$ & 1 & & & & & \\
\hline 4. Effortful control & $\begin{array}{l}.21^{*} \\
(0.05)\end{array}$ & $\begin{array}{l}.01 \\
(0.00)\end{array}$ & $\begin{array}{l}-.00 \\
(0.00)\end{array}$ & 1 & & & & \\
\hline 5. SSRT & $\begin{array}{l}-.22^{*} \\
(0.05)\end{array}$ & $\begin{array}{l}.26^{* *} \\
(0.07)\end{array}$ & $\begin{array}{l}.17^{\dagger} \\
(0.03)\end{array}$ & $\begin{array}{l}-.10 \\
(0.01)\end{array}$ & 1 & & & \\
\hline 6. Sex & .14 & -.07 & $-.17^{\dagger}$ & .16 & -.13 & 1 & & \\
\hline 7. Age & .15 & -.14 & -.08 & -.04 & -.09 & .01 & 1 & \\
\hline 8. Maternal education & -.14 & -.00 & .08 & -.14 & .07 & -.16 & $-.21^{*}$ & 1 \\
\hline$M$ & 36.76 & 1.90 & 2.42 & 3.55 & 261.69 & & 10.61 & \\
\hline$S D$ & 2.70 & 0.63 & 0.88 & 0.55 & 59.38 & & 1.03 & \\
\hline$\alpha$ & .68 & .81 & .88 & .88 & & & & \\
\hline
\end{tabular}

Note. Trust = trust in the caregiver's support; SSRT = stop-signal reaction time; Maternal education = maternal level of education; Sex is dummy coded (boy = 0; girl = 1); Maternal level of education is an ordinal variable (elementary school degree $=1$; high school degree $=2$; post high school technical training or technical bachelor's degree $=3$; master's degree $=4$ ).

${ }^{* * *} p<.001, * * p<.01, * p<.05,{ }^{\dagger} p<.10$ 
Table 2

Descriptive statistics of the Stop-Signal Task variables $(n=104)$

\begin{tabular}{llllllll}
\hline & $\mathrm{p}(\mathrm{acc} \mid \mathrm{gs})$ & $\mathrm{p}$ (miss|gs) & $\mathrm{p}$ (respond|ss) & gsrt & SSD & SSRT & srrt \\
\hline$M$ & .97 & .01 & .48 & 643.39 & 356.15 & 261.69 & 555.93 \\
$S D$ & .03 & .02 & .04 & 106.07 & 134.54 & 59.38 & 92.87 \\
\hline
\end{tabular}

Note. $p(\mathrm{acc} \mid \mathrm{gs})=$ the probability of responding correct on go-signal trials; $p$ (miss $\mid \mathrm{gs})=$ the probability of missing a response on go-signal trials; $\mathrm{p}($ respond $\mid s s)=$ the probability of responding on stop-signal trials; gsrt = go-signal reaction time; SSD = stop-signal delay; SSRT = stop-signal reaction time; srrt = signal-respond reaction time. The distinction between $\mathrm{p}$ (acc|gs) and $\mathrm{p}$ (miss $\mid \mathrm{gs})$ is consistent with previous research: $\mathrm{p}(\mathrm{acc} \mid \mathrm{gs})=$ (\# correctly executed go responses)/ $(\#$ correctly executed responses + \# incorrectly executed responses); $\mathrm{p}$ (miss $\mid \mathrm{gs})$ = (\# missed go responses)/ (\# correctly executed responses + \# incorrectly executed responses + \# missed go responses). 
Figure 1. Example of a trial course in the Stop-Signal Task (Verbruggen et al., 2008). On go-trials children are required to discriminate between two go-stimuli (press left for a square, press right for a circle). On stop-trials, the go-stimulus is followed by an auditory stop-signal. Children are instructed to inhibit their response whenever they hear that stop-signal. The stop-signal delay (SSD), the time between the go-stimulus and stop-signal, is variable throughout the experimental procedure, continuously adjusted based on children's success and failures in inhibiting their response on stopsignal trials.

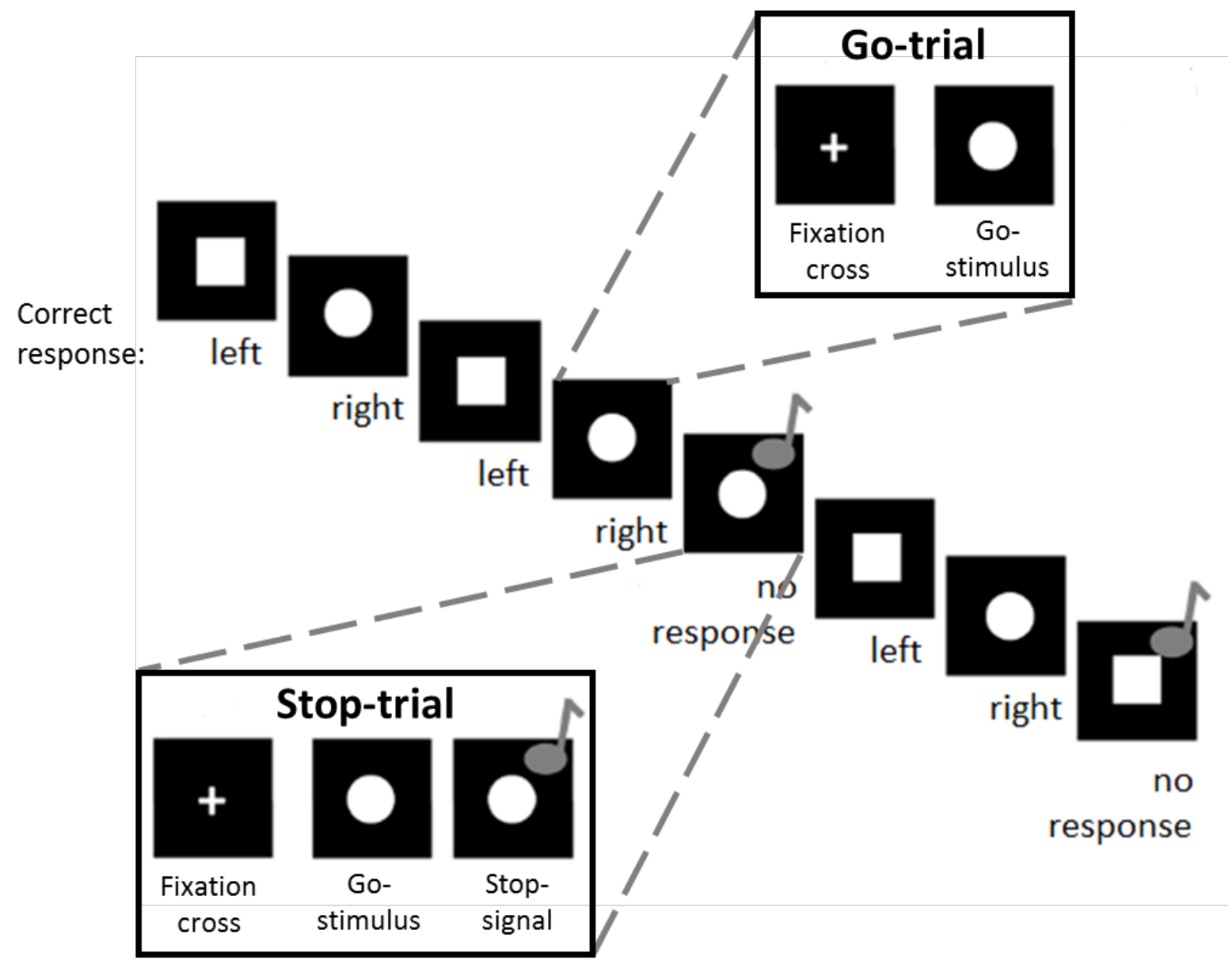

